\title{
Emerging function and potential diagnostic value of circular RNAs in cancer
}

\author{
Xianglun Cui ${ }^{1}$, Jianxun Wang ${ }^{2}$, Zongjun Guo ${ }^{3}$, Mengyang Li ${ }^{2}$, Mingyu Li ${ }^{1}$, Si Liu' ${ }^{1}$, Haoran Liu', Wenjing Li', \\ Xunhua Yin', Jiaping Tao ${ }^{1}$ and Wenhua $\mathrm{Xu}^{1 *}$
}

\begin{abstract}
As a novel class of endogenous RNAs, circRNAs, have a covalently closed continuous loop, with neither a 5 'to 3'polarity, nor a polyadenylated tail. Numerous circRNAs have been characterized by abundance, stabilization, conservation, and exhibit tissue/developmental stage-specific expression. Furthermore, circRNAs play vital roles in tumorigenesis and metastasis, such as functioning as a ceRNA or miRNA sponge, interacting with protein and encoding protein. Increasing evidence has revealed that it potentially serves as a required novel biomarker for cancer diagnosis. This review summarized the latest research on circRNAs, including its classification and biogenesis, mechanism and functions, as well as circRNAs in different cancers, as a potential biomarker.
\end{abstract}

Keywords: Circular RNA, Cancer, Biogenesis, Function, Biomarker

\section{Background}

As a novel class of long non-coding RNAs, circular RNAs (circRNAs) are widely expressed in the tree of life [1-3]. circRNAs have originally been considered as non-functional accidental by-products of aberrant splicing [4], which has not received enough attention. With the emergence of next-generation sequencing, especially RNA sequencing technology, numerous circRNAs have been found to be extensively expressed in eukaryotic cells. circRNAs are single-stranded transcripts derived from exons, introns, or intergenic regions that have a covalently closed continuous loop without a polyadenylated tail [5]. Due to the closed structure, circRNAs have been shown to be highly stable. Numerous circRNAs display evolutionary conservation, and the expression profiles are cell type- or developmental stage-specific.

Cancer is one of the most serious and life-threatening diseases, which has high morbidity and mortality worldwide, and a high frequency of metastasis and recurrence. Hence, there is an urgent need to identify potential biomarkers for prognosis predication, and determine new targets to design more powerful therapeutic approaches. Various studies have suggested that circRNAs are of

\footnotetext{
*Correspondence: qd.wh@163.com

'Department of Inspection, The medical faculty of Qingdao University, Qingdao 266003, China

Full list of author information is available at the end of the article
}

great significance in tumorigenesis and metastasis, such as lung cancer [6,7], colorectal cancer [8,9], gastric cancer [10, 11], hepatocellular carcinoma (HCC) [12-15], breast cancer [16, 17], and so on. The present study summarized the latest research on circRNAs, including its classification and biogenesis, mechanism and functions, as well as circRNAs in different cancers, as a potential biomarker.

\section{Classification and biogenesis of circRNAs}

According to composition, circRNAs can be classified into three categories: (a) ecircRNAs contain only exon sequences with $3^{\prime} \rightarrow 5^{\prime}$-linked, which account for over $80 \%$ of discovered circRNAs [18-20]; (b) ciRNAs only consist of intron sequences with $2^{\prime} \rightarrow 5^{\prime}$-linked intronic lariats, which are located in the nucleus [21, 22]; (c) EIciRNAs comprise of both exon and intron sequences with $3^{\prime} \rightarrow 5^{\prime}$-linked, which are nuclear localized [23].

There is another principle of classification based on breakpoint location. According to location relationship of circRNAs with adjacent coding RNA, they are classified into five types: exonic, intronic, antisense, sense overlapping and intergenic. The first two kinds, like ecircRNAs and ciRNAs, composed of introns and exons. Antisense: derived from the opposite strand, whose sequences overlap with the linear mRNA. Sense overlapping: composed of same sequences as the linear mRNA, 
but not classified into exonic or intronic. Intergenic: consists of sequences located in noncoding region [24].

After being synthesized by RNA polymerase II, the precursor mRNAs (pre-mRNAs) are spliced and the introns are removed, alternatively joining the exons to generate linear mRNAs [25]. CircRNAs are also generated from pre-mRNAs through different mechanisms. There are three biogenesis mechanisms described below (Fig. 1).

\section{Spliceosome-dependent lariat-driven circularization}

Exon circulation is spliceosome (or at least U1)-dependent as revealed by mutation of the $5^{\prime}$ splice sites [26]. In this model, the spliceosomes are assembled at back-splicing site to promote the joining of the downstream 5 'donor sites with the upstream 3'acceptor sites. The lariat is subsequently processed by internal splicing, which finally results in the release of ecircRNAs or EIciRNAs. CircRNAs biogenesis and canonical splicing compete with each other [26]. Besides, the efficiency of backsplicing is much lower than that of linear splicing [27]. Backsplicing may occur post-transcriptionally, in which the circulation is an exon-containing lariat produced by exon skipping [18]. In addition, backsplicing can also occur co-transcriptionally, and the circular production from nascent mRNA does not need a polyadenylation signal [28]. The backsplicing involves single exon $[18,19]$ or several exons [20] with intervening introns.

Intron is nucleotide sequence between exons that is removed by RNA splicing during maturation of mRNA. However, some introns containing special motif escape from identification of debranching enzyme and form intron-derived ciRNAs. The essential motif consist of 7-nt GU-rich element located near the 5'splice site, and 11-nt C-rich element near the branch point [29]. As special ciRNAs, tricRNAs are derived from pre-tRNAs splicing and consist of intronic sequences. The biogenesis of tricRNAs conservatively exists in both archaea and eukaryotes relies on the splicing endonuclease complex, which can recognize the bulge-helix-bulge (BHB) sequence motif and cleave pre-tRNAs. Subsequently, exon termini link with each other to form a mature tRNA, and intron termini are ligated together to form tricRNA [30].

\section{Intron-pairing circulation}

The pairing between two introns that flank the circularized exons, which have a complementary inverted

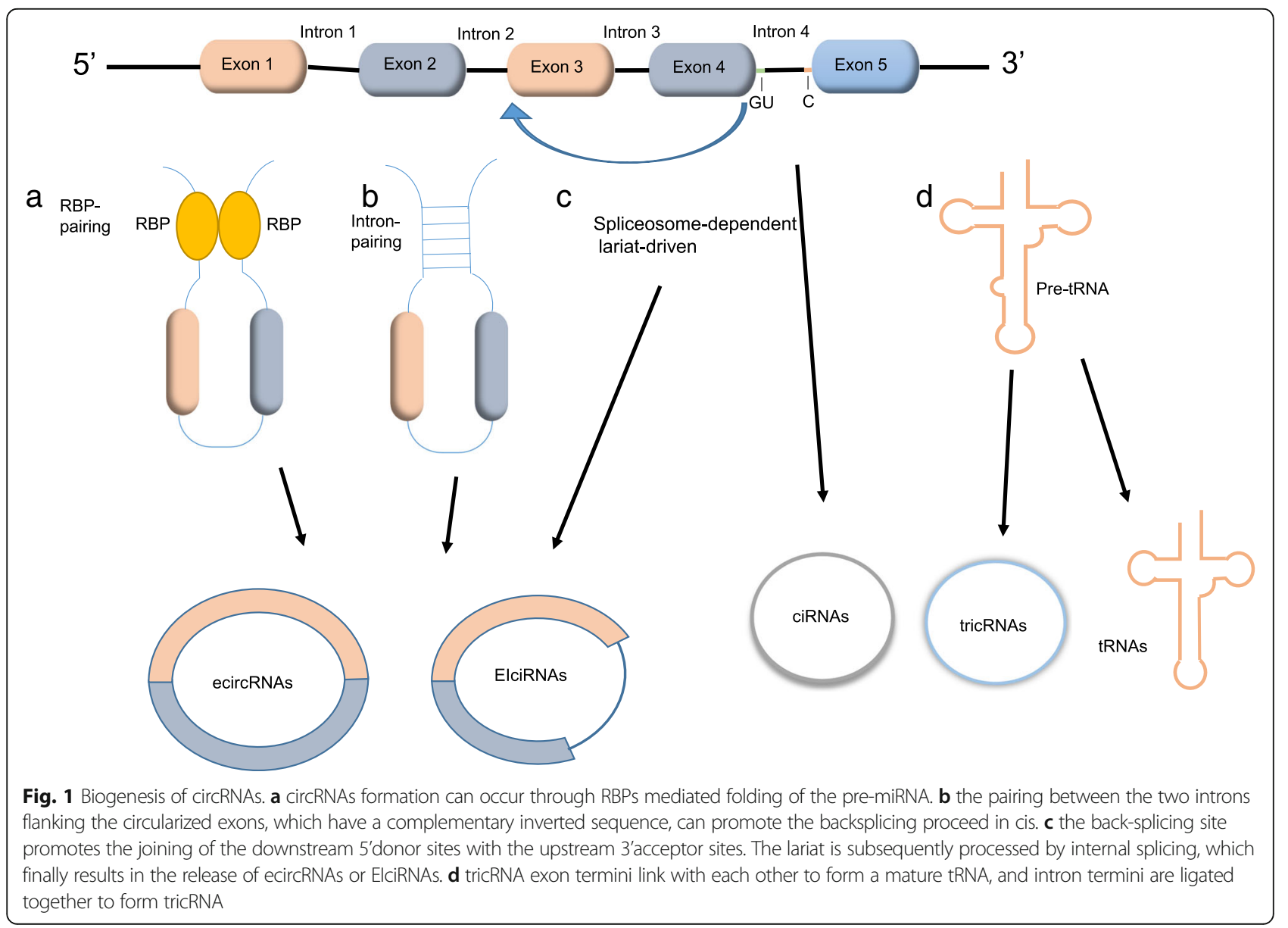


sequence, can promote the backsplicing proceed in cis [31]. The paratactic intronic structure makes the splice donor close to the splice acceptor, and facilitates the nucleophilic attack and cleavage. One of the complementary repeats is Alu elements [32], which exist in more than $10 \%$ of the human genome. Alu elements derived from introns that flank circularized exons are more likely to complement, compared to other origins. Besides, complementary Alu elements are six-fold more likely present within flanking intron of circularized exons [1]. The competition between different-located reverse complementary sequences leads to production of diverse circRNA isoforms from a single gene. Furthermore, RNA pairing can occur at non-repetitive complementary sequences [31]. It has been reported that flanking sequence or structural complementarity is absent in Drosophila RNA circulation. Similarly, only a small proportion of circRNAs possess flanking intronic complementary sequences in rice. Moreover, complementary sequences not less than 30-40 nucleotides are able to assist circRNA biogenesis [33].

\section{RNA-binding proteins (RBP)-induced circulation}

circRNA formation can occur through RBPs mediated folding of the pre-miRNA. RBPs, including Muscleblind (MBL) [26], Quaking (QKI) [34], Fused-in sarcoma (FUS) [35], are able to increase the rate of circulation by bridging relevant intronic sequences. The dimerization of RBPs, which binding with up- and downstream of the circularized exon, brings the $3^{\prime}$ and $5^{\prime}$ end of the circularized exons into close proximity and promotes their splicing. The flanking introns of circMBL contain conserved MBL binding sites. Moreover, the MBL interacts with its own pre-mRNA and stimulates cognate circRNA production. Conversely, mutation of the MBL binding sites evidently reduces circMBL production [26]. Regulated during epithelial-mesenchymal transition, QKI dynamically modulates the production of more than one-third of abundant circRNAs. Moreover, the RNAand DNA-binding protein FUS binds to circularizing exon-intron junctions, and it regulates the production of 136 circRNAs in in vitro-derived mouse motor neurons. In the contrary, there are two RBPs: ADAR1 and DHX9. As a negative regulation factor, these reduce the formation of circRNAs. Furthermore, double-stranded RNA-specific adenosine deaminase (ADAR) has been found to diminish circRNA expression through the adenosine-to-inosine (A-to-I) editing activity, which makes RNA pairs anneal and reduces complementarity and backsplicing $[32,36]$. Moreover, the nuclear RNA helicase DHX9 can interact with inverted-repeat Alu elements, downregulating Alu elements-induced intron pairing.

\section{Mechanism and function of circRNAs in cancer}

Recent studies indicate that circRNAs play a vital role in physiological and pathological processes at the post-transcription or transcription level. Here, we summarized the function and mechanism of circRNAs in cancer (Fig. 2).

\section{As competing endogenous RNAs or miRNA sponges}

Competing endogenous RNA (ceRNA) is described as a complex post-transcriptional regulatory network mediated by sequestrating miRNAs [37, 38]. The hypothesis shows that miRNA activity can be reduced by transcripts containing miRNA response elements (MREs), subsequently upregulating miRNA target expression. Apart from mRNA, transcribed pseudogenes [38] and long noncoding RNA (lncRNA) [39], numerous studies have found that many circRNAs regulate miRNA network as ceRNAs $[2,40]$. Furthermore, it has been shown that the majority of circRNAs are principally localized in the cytoplasm, suggesting that circRNAs may function as a miRNA sponge to sequestrate miRNAs (Fig. 2a). There are two characterized circRNAs,CiRS-7 and circSRY,verified this hypothesis. CiRS-7 (circRNA sponge for miR-7) contains more than 60 conserved miR-7 target sites, which are predominantly expressed in human and mouse brain [2],. CircSRY contains 16 putative miR-138 target sites that functions as miR-138 sponges [41].

Various circRNAs function as miRNAs sponges in tumorigenesis and progression. Hsa_circ_0012673 functions as a miRNA sponge of miR-22, which targets erb-b2 receptor tyrosine kinase 3 (ErbB3), promoting lung adenocarcinoma (LAC) cell proliferation [42]. As a tumor suppressor, circLARP4 is downregulated in gastric cancer (GC) tissues, suppressing gastric tumorigenesis and progression by sponging miR-424 and increasing LATS1 expression [10]. WJ Huang et al. demonstrated that hsa_circ_0000977 interacts with has-miR-874-3p, and subsequently promotes the expression of PLK1 in pancreatic ductal adenocarcinoma cancer [43]. In hepatocellular carcinoma, circHIPK3 functions as a miRNA sponge of miR-124, which sequentially upregulates the expression of AQP3, and promotes cell proliferation and migration [12]. Both circGFRA1 and GFRA1 are upregulated in triple negative breast cancer (TNBC), and circGFRA1 functions as a ceRNA to regulate GFRA1 expression by decoying miR-34a [16]. Chengdi Yang observed that circ-ITCH suppressed the aggressive biological behaviors of bladder cancer (BCa), and upregulated the expression of p21 and PTEN through decoys miR-17 and miR-224 [44]. The expression of circ-SHKBP1 is elevated in glioma-exposed endothelial cells (GECs), which functions as a ceRNA via the miR-544a/FOXP1 or miR-379/FOXP2 pathway [45]. Furthermore, L Chen et al. discovered that circRNA_100290 


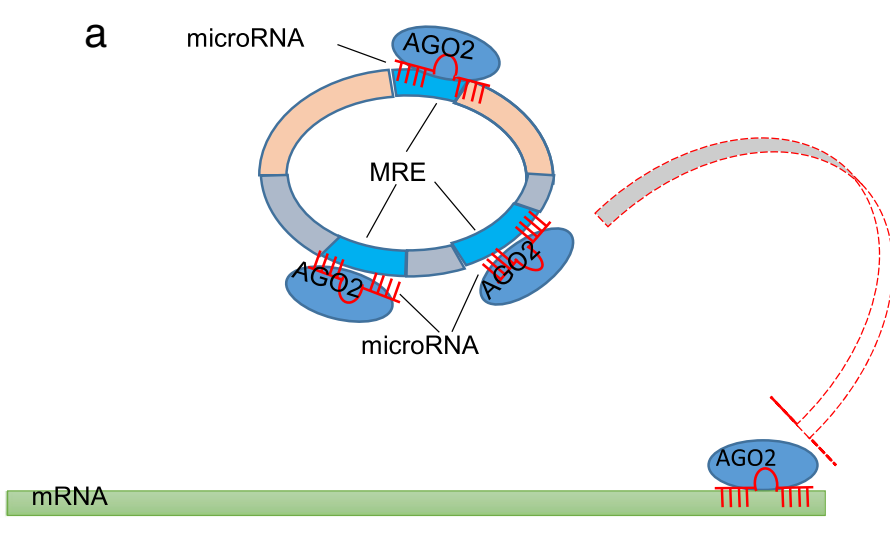

miRNA sponge

b

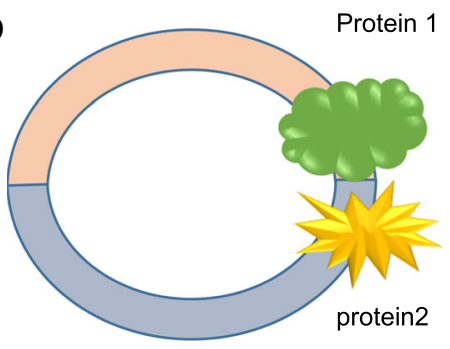

CircRNAs-Protein interaction

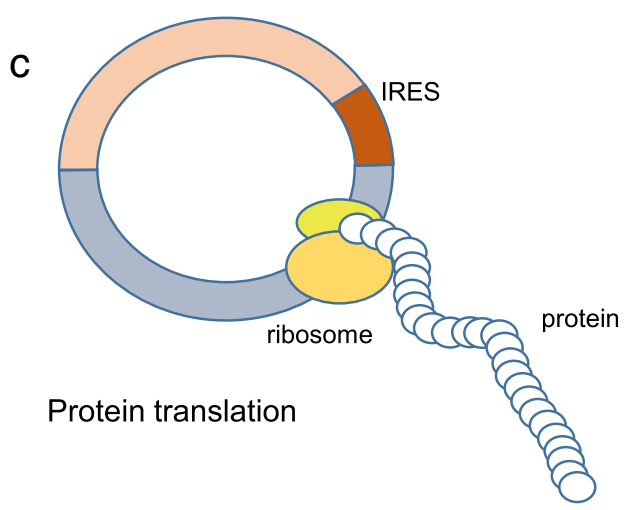

protein

Fig. 2 Functions of circRNAs. a miRNA sponge circRNAs can reduce miRNA activity by transcripts containing MREs, subsequently upregulating miRNA target expression. $\mathbf{b}$ CircRNAs-Protein interaction The interaction between circRNAs and proteins can facilitate the interaction of multiple proteins. c Protein translation circRNAs containing ORF and IRES have the potential to participant in translation

was elevated in OSCC tissues, which upregulates CDK6 expression through decoying miR-29b family members, playing a crucial role in OSCC progression such as tumor invasion and metastasis [46]. Upregulated circUBPA2 promotes osteosarcoma growth and inhibits apoptosis by downregulating the expression of miR-143, consequently raising the expression of anti-apoptosis Bcl-2 [47].

\section{Protein translation}

Although defined as a subclass of non-coding RNAs, increasing evidence have demonstrated that circRNAs have potential to participate in translation [48, 49] (Fig. 2b). It can be presumed that a protein-translated circRNA when some of the following features are present: (A) circRNAs have ORF with sufficient length, which is essential for linear mRNA protein translation; (B) it has the spanning backsplicing junction ORF; (C) some of the necessary regulation elements are present to the translation initiation upstream ORF, such as the internal ribosome entry site (IRES) element, and the N6-methyladenosine (m6A) modifications near the start codon [50].
Recently, at least two cases offer important evidence for the existence of the translation of endogenous circRNA-encoded peptides: circFXBW7 and cricSHPRH. These are of great significance in tumorigenesis and progression. Y Yang et al. revealed that circFXBW7 can encode a novel 21-KDa protein, which was named, FBXW7-185aa. A dual luciferase vector system constructed with full length or truncated putative circ-FBXW7 IRES sequences was used to test for IRES activity. The result revealed that only the full length circFBXW7 IRES group can induce the highest Luc/Ruc activity. Next, the circ-FXBW7 vector and other control vectors were transfected into human cells, and FBXW-185aa was detected by a specific antibody and liquid chromatography tandem-mass spectrometry. The result suggests that circ-FBXW7 has the potential to encode a novel protein. The protein FBXW7-185aa functions as a tumor suppressor by competitively binding with USP28, and preventing USP28 binding to FBXW7 $\alpha$, subsequently inhibiting USP28-induced c-myc stabilization. Circ-FBXW7 and FBXW7-185aa were downregulated in glioblastoma, and 
suppress proliferation and cell cycle acceleration [51]. Another example is circSHPRH, which is generated by back-splicing exons 26-29 from the SHPRH gene, and encodes a 17 KDa protein SHPRH-146aa. SHPRH-146aa protects the full-length SHPRH from DTL-induced ubiquitination, while the latter sequentially ubiquitinates proliferating cell nuclear antigen (PCNA) as an E3 ligase. Both circSHPRH and SHPRH-146aa were downregulated in glioblastoma, which suppress cell proliferation and tumorigenesis [52]. In the summary, both circ-FBXW7 and circ-SHPRH contain the spanning junction ORF and IRES, and play an essential role in glioma tumorigenesis by encoding a protein.

\section{CircRNA-protein interaction}

There are conserved, protein-binding sequences in some circRNAs which can be demonstrated by the co-localization of circRNAs and proteins. The interaction between circRNAs and proteins can regulate transcription of parental genes, facilitate the interaction of multiple proteins, as well as alter the subcellular localization of proteins. CircRNAs can function as a protein scaffolding to facilitate contact between two or more proteins (Fig. 2c). CircFoxo3 is perhaps the best example, which binds with cyclin-dependent kinase inhibitor 1 (p21) and cyclin-dependent kinase 2 (CDK2), forming a ternary complex. P21 can inhibit CDK2 activity and act as a regulator of cell cycle progression at the $\mathrm{G} 1$ and $\mathrm{S}$ phase. Circ-Foxo3 can facilitate the interaction between p21 and $C D K 2$, resulting in the inhibition of the cell cycle [53]. Q Yang et al. observed that circAmotl1 and c-myc co-localizes to the nucleus, and the interaction between these two induces c-myc nuclear translocation and prevents degradation. CircAmotl1 is significantly increased in breast cancer and promotes tumorigenesis by interacting with c-myc [17].

\section{Other functional mechanism}

Cancer-associated chromosomal translocations not only encode oncogenic fusion proteins, but also produce fusion circRNAs. J Guarnerio et al. found two aberrant f-circRNAs produced by chromosomal translocation: f-circM9 and f-circPR. These are correlated with the tumorigenesis and progression of hematological tumors. The expression of $\mathrm{f}$-circRNAs in cancer cells is of great significance to cell survival and therapy resistance [54]. In addition, $\mathrm{S}$ Tan et al. discovered that endogenous F-circEA derived from EML4-ALK fusion gene was existed in H2228 cells with the EML4-ALK variant 3b translocation. Furthermore, F-circEA is not only existed in NSCLC tissues but also in the plasma of the patients with the EML-ALK translocation [7].

\section{CircRNAs in cancer}

Numerous circRNAs have been found to be dysregulated in tumor tissues, playing oncogenic or tumor-suppressor roles. Growing evidence show that circRNAs are significantly correlated with malignant behavior of tumor cells and clinical stage. Here, we summarized recent studies about regulatory networks and vital function of circRNAs in several mortal cancer (Table 1).

\section{Lung adenocarcinoma}

Lung cancer is the leading cause for cancer-related death worldwide, and non-small cell lung cancer accounts for more than $80 \%$ of all lung cancer cases $[55,56]$. LAC is the most common type in recent decades. The expression of has_circ_0012673 is significantly increased in LAC tissues, promoting LAC cell proliferation and tumor growth via the hsa_circ_0012673/miR-22/ErbB3 axis [42]. X Zhu et al. observed that cell proliferation was suppressed, cell apoptosis was induced, and cell migration and invasion was inhibited after silencing hsa_circ_0013958 [57]. In addition, Qiu et al. demonstrated that elevated circPRKCI promoted cell proliferation and migration through the circPRKCI-miR-545/589-E2F7 axis, positively correlated with tumor size and TNM stage. Treatment of si-circPRKCI significantly inhibited growth of SPC-A1-derived tumor xenografts and patient-derived tumor xenografts in vivo [6]. Similarly, circRNA_102231 promotes lung cancer cells proliferation and invasion ability in vitro. Moreover, increased circRNA_102231 is significantly associated with the advanced TNM stage, lymph node metastasis, and poor overall survival of lung cancer patients [58]. Hsa_circ_0007385 is up-regulated in NSCLC tissues and cells, acting as a sponge of miR-181. Hsa_circ_0007385 silencing suppresses the proliferation activity, colony-forming ability, migration and invasion of NSCLC cells in vitro and inhibits the tumor growth in vivo [59]. X Dai et al. discovered that circ0006916 was decreased in lung cancer cells and tissues, and inhibited cell proliferation by regulating cell cycle progression but not apoptosis [60]. F-circEA increases cell migratory and invasion ability, and dose not participate in cell proliferation and colony formation [7]. In addition, circFARSA, hsa_circ_103809, circFADS2 also play significant roles in lung cancer progression [61-63].

\section{Colorectal cancer}

Colorectal cancer $(\mathrm{CRC})$ is the third most frequent cause of cancer-related death in America [56]. CircHIPK3 knockdown significantly inhibits cell proliferation, and colony-forming ability, migration and invasion. Likewise, circHIPK3 silencing suppresses CRC growth and metastasis in xenograft animal models, and exhibits an additive effect on tumor repression [8]. CircCCDC66 serves 
Table 1 summary of the expression and signaling pathways of circRNAs involved in cancer

\begin{tabular}{|c|c|c|c|c|}
\hline Cancer type & CircRNA & Funtion & $\begin{array}{l}\text { Expression } \\
\text { in tumors }\end{array}$ & References \\
\hline \multirow{10}{*}{$\begin{array}{l}\text { Lung } \\
\text { adenocarcinoma }\end{array}$} & hsa_circ_0012673 & promotes LAC cell proliferation and tumor growth by decoying miR-22 & Up & [42] \\
\hline & hsa_circ_0013958 & promotes cell proliferation, migration and invasion by sponging miR-134 & Up & [57] \\
\hline & CirCPRKC1 & $\begin{array}{l}\text { positively correlated with tumor size and TNM stage, promotes } \\
\text { cell proliferation and migration by regulating miR-545/589 }\end{array}$ & Up & [6] \\
\hline & circRNA_102231 & $\begin{array}{l}\text { associated with the advanced TNM stage, lymph node metastasis and } \\
\text { poor overall survival, promotes cell proliferation and invasion ability }\end{array}$ & Up & [58] \\
\hline & has_circ_0007385 & $\begin{array}{l}\text { promotes the proliferation activity, colony-forming ability, migration and } \\
\text { invasion of NSCLC cells in vitro and the tumor growth in vivo by } \\
\text { decoying miR-181 }\end{array}$ & Up & [59] \\
\hline & circ0006916 & inhibits cell proliferation by regulating cell cycle progression & Down & [60] \\
\hline & f-circEA & promotes cell migration and invasion & Up & [7] \\
\hline & circFARSA & $\begin{array}{l}\text { promotes cell migration and invasion by sponging miR-330-5p } \\
\text { and miR-326 }\end{array}$ & Up & [63] \\
\hline & hsa_circRNA_103809 & $\begin{array}{l}\text { promotes cell proliferation and invasion in vitro and tumor growth } \\
\text { in vivo by } \\
\text { sponging miR-4302 }\end{array}$ & Up & [61] \\
\hline & circFADS2 & $\begin{array}{l}\text { correlated with advanced TNM stage, lymph node metastasis, poor } \\
\text { differentiation and shorter overall survival of NSCLC patients. promotes } \\
\text { cell proliferation and } \\
\text { invasion ability }\end{array}$ & Up & [62] \\
\hline \multirow[t]{5}{*}{$\begin{array}{l}\text { Colorectal } \\
\text { cancer }\end{array}$} & circHIPK3 & $\begin{array}{l}\text { promotes cell proliferation, and colony-forming ability, migration and } \\
\text { invasion by decoying miR-7 invasion by decoying miR-7 }\end{array}$ & Up & [8] \\
\hline & circCCDC66 & $\begin{array}{l}\text { promotes cancer cell proliferation, migration and metastasis in vitro } \\
\text { and in vivo by sponging miRNA-33b and miR-93 }\end{array}$ & Up & [9] \\
\hline & ciRS-7 & $\begin{array}{l}\text { positively correlated with advanced tumor stage, tumor depth and } \\
\text { metastasis by downregulating miR-7 }\end{array}$ & UP & [64] \\
\hline & circBANP & related with cell proliferation and colony formation ability & Up & [65] \\
\hline & hsa_circ_0014717 & $\begin{array}{l}\text { correlated with TNM stage, distal metastasis, and prognosis of CRC } \\
\text { patients, antagonizes cell proliferation and colony-forming ability, as } \\
\text { well as induces cell cycle arrest at G0/G1 phase }\end{array}$ & Down & [66] \\
\hline \multirow[t]{3}{*}{ Gastric cancer } & has_cric_0000096 & $\begin{array}{l}\text { inhibits gastric cancer proliferation and migration by suppressing cyclin } \\
\text { D1, CDK6, MMP-2 and MMP-9 }\end{array}$ & Down & [68] \\
\hline & circPVT1 & promotes cell proliferation by sponging miR-125 & Up & [11] \\
\hline & circLARP4 & $\begin{array}{l}\text { Impairs GC cell proliferation and invasion, associated with tumor size, } \\
\text { lymphatic metastasis and the therapeutic outcomes of GC patients by } \\
\text { regulating miR-424 }\end{array}$ & Down & [10] \\
\hline \multirow[t]{3}{*}{$\begin{array}{l}\text { Pancreatic } \\
\text { cancer }\end{array}$} & hsa_circ_0000977 & $\begin{array}{l}\text { associated with poor prognosis in PDAC patients, promotes cell } \\
\text { proliferation and colony formation ability by sponging hsa-miR-874-3p }\end{array}$ & Up & [43] \\
\hline & circ-LDLRAD3 & associated with venous invasion, lymphatic invasion and metastasis & Up & [70] \\
\hline & CircPDE8A & $\begin{array}{l}\text { correlated with lymphatic invasion, T factor and TNM stage, promotes } \\
\text { migration or invasion, cell proliferation and EMT }\end{array}$ & Up & [71] \\
\hline \multirow[t]{6}{*}{$\begin{array}{l}\text { Hepatocellular } \\
\text { carcinoma }\end{array}$} & circMTO1 & $\begin{array}{l}\text { correlates with the poor survival of patients, inhibits cell proliferation and } \\
\text { invasion by decoying miR-9 }\end{array}$ & Down & [13] \\
\hline & circARSP91 & $\begin{array}{l}\text { AR suppresses circARSP91expression by upregulating the expression } \\
\text { of ADAR1 }\end{array}$ & Down & [14] \\
\hline & CSMARCA5 & $\begin{array}{l}\text { correlated with advanced tumor stage, tumor size and the presence of } \\
\text { microvascular invasion through sponging miR-17-3p an miR-181b-5p }\end{array}$ & Down & [15] \\
\hline & circ_0067934 & $\begin{array}{l}\text { promotes cell proliferation and metastasis in vitro and in vivo by } \\
\text { regulating miR-1324 }\end{array}$ & Up & [72] \\
\hline & circRNA_100,338 & $\begin{array}{l}\text { correlated with decreased cumulative survival rate, increased vascular } \\
\text { invasion and lung metastasis in HCC patients by suppressing miR-141-3p }\end{array}$ & Up & [73] \\
\hline & circHIPK3 & $\begin{array}{l}\text { promotes the proliferation and migration of HCC cells, as well as xenograft } \\
\text { tumor growth in vivo by downregulating miR-124 }\end{array}$ & Up & [12] \\
\hline
\end{tabular}


Table 1 summary of the expression and signaling pathways of circRNAs involved in cancer (Continued)

\begin{tabular}{|c|c|c|c|c|}
\hline Cancer type & CircRNA & Funtion & $\begin{array}{l}\text { Expression } \\
\text { in tumors }\end{array}$ & References \\
\hline & circC3P1 & $\begin{array}{l}\text { represses the migration and invasion of HCC cells in vitro, and inhibits } \\
\text { HCC cells proliferation and lymphatic metastasis in vivo by sponging } \\
\text { miR-4641 }\end{array}$ & Down & [74] \\
\hline \multirow[t]{5}{*}{ Breast cancer } & circGFRA1 & $\begin{array}{l}\text { correlated with tumor size, TNM staging, lymph node metastasis and } \\
\text { histological grade, promotes cell proliferation and the colony-forming } \\
\text { ability by decoying miR-34a }\end{array}$ & Up & [16] \\
\hline & circAmotl1 & $\begin{array}{l}\text { increases invasive capacity, reduces number of apoptosis cells, and } \\
\text { augmentes tumor-forming capacity by promoting c-myc } \\
\text { nucleus-translocation }\end{array}$ & Up & [17] \\
\hline & circRNA-000911 & $\begin{array}{l}\text { suppresses the invasive capacity and proliferation, reduces colony } \\
\text { formation ability and elevates the proportion of apoptotic cells by } \\
\text { sponging miR-449a }\end{array}$ & Down & [75] \\
\hline & cricABCB10 & $\begin{array}{l}\text { promotes cell proliferation and colony formation capacity by } \\
\text { downregulating miR-1271 }\end{array}$ & Up & [76] \\
\hline & hsa_circ_0011946 & $\begin{array}{l}\text { correlated with RFC3 expression, promotes migration and invasion of } \\
\text { MCF-7 cell }\end{array}$ & Up & [77] \\
\hline \multirow[t]{4}{*}{ Bladder cancer } & circ-ITCH & $\begin{array}{l}\text { suppresses cell proliferation, migration and invasion in vitro, as well as } \\
\text { tumorigenesis in vivo, through sponging miR-17 and miR-224 }\end{array}$ & Down & [44] \\
\hline & circRNA-MYLK & $\begin{array}{l}\text { increases the tumorigenicity of } \mathrm{BC} \text { cells, distinct metastatic lesions in } \\
\text { mice lungs and tumor microvessels by decoying miR-29a/ }\end{array}$ & Up & [79] \\
\hline & circHIPK3 & $\begin{array}{l}\text { suppresses the aggressiveness and metastasis of bladder cancer cells in } \\
\text { vitro and in vivo by targeting miR-558 }\end{array}$ & Down & [80] \\
\hline & Cdr1as & $\begin{array}{l}\text { inhibits the migration and invasion capabilities, as well as induces cell } \\
\text { cycle arrest }\end{array}$ & Down & [81] \\
\hline \multirow[t]{4}{*}{ Glioblastoma } & circ-FBXW7 & $\begin{array}{l}\text { associated with glioblastoma patient overall survival, inhibits proliferation } \\
\text { and cell cycle acceleration by encoding FBXW7-185aa }\end{array}$ & Down & [51] \\
\hline & circSHPRH & $\begin{array}{l}\text { encodes SHPRH-146aa which can protect SHPRH and reduce proliferation } \\
\text { and the malignant phenotype }\end{array}$ & Down & [52] \\
\hline & circ-SHKBP1 & $\begin{array}{l}\text { promotes the viability, migration and tube formation of glioma-exposed } \\
\text { endothelial cells by sponging miR-544a or miR-379 }\end{array}$ & Up & [45] \\
\hline & cric-TTBK2 & $\begin{array}{l}\text { promotes cell proliferation, migration and invasion, but inhibits the } \\
\text { apoptosis of glioma cells by regulating miR-217 }\end{array}$ & Up & [82] \\
\hline \multicolumn{5}{|l|}{ Other cancers } \\
\hline \multirow[t]{2}{*}{$\begin{array}{l}\text { Oral squamous } \\
\text { cell carcinomas }\end{array}$} & circRNA_100290 & $\begin{array}{l}\text { promotes cell proliferation in vitro and the growth of tumors in vivo by } \\
\text { decoying miR-29b }\end{array}$ & Up & [46] \\
\hline & circDOCK1 & inhibits cell apoptosis by sponging miR-196a-5p & Up & [83] \\
\hline \multirow[t]{5}{*}{ Osteosarcoma } & cricUBAP2 & $\begin{array}{l}\text { correlated with tumor stages, promotes cell proliferation in vitro and cell } \\
\text { growth } \\
\text { in vivo by downregulating miR-143 }\end{array}$ & Up & [47] \\
\hline & circ-NT5C2 & $\begin{array}{l}\text { correlated with tumor volume and weight in a mice model, promotes } \\
\text { cell proliferation and invasion in vitro by decoying miR-448 }\end{array}$ & Up & [84] \\
\hline & circRNA_0009910 & $\begin{array}{l}\text { promotes cell proliferation and inhibits apoptosis by sponging } \\
\text { miR-449a/IL6R }\end{array}$ & Up & [85] \\
\hline & has_circ_0001564 & $\begin{array}{l}\text { promotes cell viability and the colony formation vitality by decoying } \\
\text { miR-29c-3p }\end{array}$ & Up & [87] \\
\hline & circNASP & $\begin{array}{l}\text { promotes the proliferation and invasion of OS cells by sponging } \\
\text { miR-1253 }\end{array}$ & Up & [86] \\
\hline $\begin{array}{l}\text { Hematological } \\
\text { tumors }\end{array}$ & f-circM9, f-circPR & $\begin{array}{l}\text { contributes to cellular transformation, and promotes cell viability and } \\
\text { resistance upon therapy }\end{array}$ & Up & [54] \\
\hline
\end{tabular}

as a miRNA sponge of miRNA-33b and miR-93, promoting cancer cell proliferation, migration and metastasis in vitro and in vivo [9]. In addition, ciRS-7 is overexpressed in CRC tissues, and positively correlated with advanced tumor stage, tumor depth and metastasis in CRC patients [64]. M $\mathrm{Zhu}$ et al. discovered that the proliferation and colony 
formation ability of the si-circ-BANP group was markedly repressed, when compared with negative control group [65]. Hsa_circ_0014717 is down-regulated in CRC tissues compared with adjacent normal tissues and closely correlated with TNM stage, distal metastasis, and prognosis of CRC patients. Moreover, hsa_circ_0014717 overexpression significantly antagonizes cell proliferation and colony-forming ability, as well as induces cell cycle arrest at G0/G1 phase [66].

\section{Gastric cancer}

In 2012, gastric cancer (GC) ranks third in cancer-related deaths and fourth common gastrointestinal malignancies worldwide [67]. P Li et al. found that has_cric_0000096 was significantly reduced in gastric cancer tissues and cells. It can inhibit gastric cancer proliferation and migration by suppressing the expression levels of cyclin D1, cyclin-dependent kinase (CDK) 6, matrix metalloproteinase (MMP)-2 and MMP-9 [68]. The expression of circPVT1 is upregulated in GC tissues, when compared with matched normal tissues, and promotes cell proliferation, having the potential to serve as an independent prognostic indicator [11]. As a tumor suppressor, circLARP4 is downregulated in GC tissues, and impairs GC cell proliferation and invasion. In addition, the expression level of circLARP4 is associated with tumor size, lymphatic metastasis and the therapeutic outcomes of GC patients [10].

\section{Pancreatic cancer}

Recently, the incidence and mortality of pancreatic cancer increase every year, worldwide. It is the 7th and 4th leading cause of mortality among all malignancies in China [69] and the United States [56]. WJ Huang et al. demonstrated that has_circ_0000977 is upregulated in pancreatic ductal adenocarcinoma (PDAC) tissues, and is associated with poor prognosis in PDAC patients. Hsa_circ_0000977 silencing suppresses cell proliferation, reduces colony formation ability, and induces G1/S arrest [43]. The expression of circ-LDLRAD3 is increased in both pancreatic cancer tissues and plasma in patients with pancreatic cancer. It is correlated with venous invasion in patients with pancreatic cancer [70]. Furthermore, circ-PDE8A is significantly correlated with lymphatic invasion, $\mathrm{T}$ factor and TNM stage. It promotes migration or invasion, cell proliferation and EMT via the miR-338/MACC1/MET pathway [71].

\section{Hepatocellular carcinoma}

As the fifth leading cause of mortality from cancerrelated diseases worldwide, hepatocellular carcinoma accounts for approximately $80 \%$ of primary liver cancers $[56,67]$. CircMTO1 is downregulated in HCC tissues, and correlated with the poor survival of patients. After silencing circMTO1, the level of cell proliferation and invasion is significantly increased, and the percentage of apoptosis is reduced in vitro and in animal model prepared by transplanting human HCC tissues [13]. L Shi et al. revealed that androgen receptor (AR) could regulate circRNA expression in HCC by upregulating the expression of ADAR1, which enables the suppression of RNA circulation. The AR/ADAR1/circARSP91 axis is essential to HCC initiation and gender disparity. cSMARCA5 is decreased in HCC tissues, and correlated with aggressive biological behaviors, such as poorer tumor differentiation, advanced tumor stage, tumor size and the presence of microvascular invasion [15]. Circ_0067934 is highly expressed in HCC tissues, when compared with adjacent normal tissues, and promotes cell proliferation and metastasis in vitro and in vivo via the miR-1324/ FZD5/Wnt/b-catenin axis [72]. G Chen et al.discovered that circHIPK3 promoted the proliferation and migration of HCC cells, as well as xenograft tumor growth, in vivo [12]. The ectopic expression of CircRNA_100,338 is correlated with decreased cumulative survival rate, increased vascular invasion and lung metastasis in HCC patients [73]. As a tumor suppressor, circC3P1 overexpression represses the migration and invasion of HCC cells in vitro, and inhibits HCC cells proliferation and lymphatic metastasis in vivo [74].

\section{Breast cancer}

Breast cancer is one of the leading reasons of cancer-related mortality, and the most frequent cancer that occurs in women worldwide $[56,67]$. The expression level of circGFRA1 is correlated with tumor size, TNM staging, lymph node metastasis and histological grade. The downregulation of circGFRA1 markedly impairs the proliferation potential and reduces the colony-forming ability of TNBC cells. Furthermore, the apoptosis of TNBC cells is promoted, and tumor growth is decreased in vivo upon circGFRA1 silencing [16]. Q Yang et al. demonstrated that cricAmotl1 promotes breast cancer progression, which is manifested by increased invasive capacity, reduced number of apoptosis cells, and augmented tumor-forming capacity [17]. H Wang et al. reported that circRNA-000911 suppressed the invasive capacity and proliferation of circRNA-000911-transfected cells. In addition, circRNA-000911 markedly reduces colony formation ability and elevates the proportion of apoptotic cells [75]. CricABCB10 is significantly upregulated in breast cancer tissues. In circ-ABCB10 knockdown cells, apoptosis is enhanced, and cell proliferation and colony formation capacity is suppressed [76]. Furthermore, has-circ-0011946 is significantly up-regulated in breast cancer and different breast cancer cell lines. The expression of has-circ-0011946 
is positively correlated with RFC3 expression, silencing of has_circ_0011946 inhibits migration and invasion of MCF-7 cell [77].

\section{Bladder cancer (BCa)}

$\mathrm{BCa}$ is the ninth most common carcinoma with high morbidity and mortality worldwide [78]. C Yang et al. found that circ-ITCH was reduced in $\mathrm{BCa}$ tissues and cell lines, suppressing cell proliferation, migration and invasion in vitro, as well as tumorigenesis in vivo, through the circ-ITCH/miR-17, miR-224/p21, and PTEN axis [44]. CircRNA-MYLK activates the VEGFA/ VEGFR2 and Ras/ERK signaling pathways. As a potential oncogene, it increases the tumorigenicity of $\mathrm{BCa}$ cells, distinct metastatic lesions in mice lungs and tumor microvessels [79]. In addition, circHIPK3 regulates heparanase by targeting miR-558, sequentially suppressing the aggressiveness and metastasis of bladder cancer cells in vitro and in vivo [80]. P $\mathrm{Li}$ et al.demonstrated that Cdr1as diminished the migration and invasion capabilities of bladder cancer cells, as well as induced cell cycle arrest. Moreover, Cdr1as significantly inhibits the growth of tumor xenografts in nude mice [81].

\section{Glioblastoma}

Glioblastoma is the most common intracranial tumor, and is one of the worst prognosis cancer worldwide. Circ-FBXW7 can encode a novel protein FBXW7-185aa, and patients whose glioblastoma tissues have higher circ-FBXW7 have a longer total survival time, when compared to patients with lower circ-FBXW7. Mice implanted with U251 and U373 cells that stably overexpress circ-FBXW7 exhibited much lower tumorigenicity and a longer lifetime [51]. Another protein-translating circRNA is circSHPRH, which is downregulated in $81 \%$ of glioblastoma samples, and encodes a functional protein SHPRH-146aa. The protein can prolong the half-life of full length SHPRH, and reduce proliferation and the malignant phenotype. Patients with higher SHPRH-146aa expression have a better prognosis, when compared to patients with lower SHPRH-146aa expression [52]. In addition, the expression of circ-SHKBP1 is elevated in glioma-exposed endothelial cells (GECs), and promotes the viability, migration and tube formation of GECs via the miR-544a/FOXP1 or miR-379/FOXP2 pathway via the AGGF1 itself or though the PI3K/AKT and ERK 1/2 pathways [45]. Circ-TTBK2 is upregulated in glioma tissues and cells, and promotes cell proliferation, migration and invasion, but inhibits the apoptosis of glioma cells. Meanwhile, circ-TTBK2 silencing results in the smaller tumor volume and longer survival period in experiments in vivo [82].

\section{Other cancers}

Many studies have found that circRNAs also play an important role in the pathogenesis of many other tumors. For instance, the silencing of circRNA_100290 would induce G1/S arrest, suppressing cell proliferation in vitro, and markedly inhibiting the growth of tumors in vivo [46]. Furthermore, circDOCK1 inhibits cell apoptosis via the circDOCK1/miR-196a-5p/BIRC3 axis in OSCC, and has the potential to be a biomarker and therapeutic target [83]. In osteosarcoma, elevated circUBAP2 expression can promote cell proliferation in vitro and cell growth in vivo [47]. The expression level of circ-NT5C2 is significantly correlated with the apoptosis rate, and suppresses cell proliferation and invasion in vitro and tumor volume and weight in a mice model [84]. N Deng et al. found that the expression of circRNA_0009910 is augmented in osteosarcoma cells, and correlated with cell proliferation inhibition, cell cycle arrest, and apoptosis in osteosarcoma cells [85]. In addition, circNASP silence significantly inhibits the proliferation and invasion of osteosarcoma cells, as well as induces G0/G1 stage arrest [86]. Hsa_circ_0001564 knockdown evidently impedes cell viability, represses the colony formation vitality induces G0/G1 stage arrest and promotes apoptosis [87]. Moreover, J Guarnerio et al. discovered that f-circRNAs are derived from cancer-associated chromosomal translations, which can promote tumorigenesis, and enhance cell viability and resistance to therapy [54].

\section{Circular RNAs as a biomarker in cancer}

It is known that early detection and early treatment have a very important significance to the prognosis of tumors. As mentioned above, circRNAs function primarily upstream of various regulatory networks and signaling pathways, and contribute to the implementation of early diagnosis and early treatment. CircRNAs are abundantly expressed in various tissues, and circRNA isoforms of many human transcripts are expressed at levels comparable to the canonical linear isoforms [88]. In addition, circRNAs are characterized by covalently closed loop structures and resistant to RNA exonuclease or RNase R [89], which exhibit longer half-time and more detectable than their cognate linear RNA. Furthermore, circRNAs expression are tissue- and developmental stage-specific [90]. Like widely recognized tumor biomarkers, circRNAs can also be detected in plasma and saliva [91, 92]. Therefore, circRNAs have potential as biomarkers for cancer diagnosis.

As mentioned above, various circRNAs differentially express between tumor tissues and matched normal tissues, correlated with aggressive biological behaviors. Plasma samples as a non-invasive diagnostic method, is widely used in the clinical. Here, we summarized the 
Table 2 Circular RNAs as plasma biomarker in cancer

\begin{tabular}{|c|c|c|c|c|c|c|c|}
\hline \multirow[t]{2}{*}{ circRNA } & \multirow[t]{2}{*}{ Cancer type } & \multirow[t]{2}{*}{ Expression in plasma } & \multirow[t]{2}{*}{ Clinical correlation } & \multicolumn{3}{|c|}{ ROC curve } & \multirow[t]{2}{*}{ References } \\
\hline & & & & AUC & sensitivity & Specifity & \\
\hline Hsa_circ_0013958 & LAC & up & TNM stage, lymphatic metastasis & 0.815 & 0.755 & 0.796 & {$[57]$} \\
\hline F-circEA & NSCLC & up & - & - & - & - & [7] \\
\hline Hsa_circ_000745 & GC & down & tumor differentiation & 0.775 & 0.800 & 0.633 & [93] \\
\hline $\begin{array}{l}\text { Hsa_circ_0001017 } \\
\text { /hsa_circ_0061276 }\end{array}$ & GC & Down & distal metastasis & 0.966 & 0.955 & 0.957 & [94] \\
\hline Hsa_circ_0000520 & GC & Down & TNM stage, CEA expression & 0.8967 & 0.8235 & 0.8444 & {$[95]$} \\
\hline Hsa_circ_2059 & GC & Down & distal metastasis, TNM stage, gender and age & 0.73 & - & - & [97] \\
\hline Circ-LDLRAD3 & $\begin{array}{l}\text { Pancreatic } \\
\text { cancer }\end{array}$ & Up & venous invasion, lymphatic invasion & 0.87 & 0.8033 & 0.9355 & {$[70]$} \\
\hline CircPVT1 & OS & Up & $\begin{array}{l}\text { advanced Enneking stage, chemoresistance, } \\
\text { lung metastasis }\end{array}$ & 0.871 & - & - & [98] \\
\hline Circ-KLDHC10 & CRC & Up & - & - & - & - & [99] \\
\hline Circ-PDE8A & PDAC & Up & $\begin{array}{l}\text { duodenal invasion, vascular invasion, } T \text { factor or } \\
\text { TNM stage }\end{array}$ & - & - & - & [71] \\
\hline
\end{tabular}

latest literature on the role of circRNAs, which can be detected in plasma of patients (Table 2). X Zhu et al. observed that has_circ_0013958 was significantly elevated in all LAC tissues, cells and plasma, which was correlated to TNM stage and lymphatic metastasis. In addition, the AUC of has_circ_0013958 for LAC diagnosis was 0.815 , and the sensitivity and specificity was 0.755 and 0.796 , respectively [57]. F-circEA can be specifically detected in the plasma and tumor tissues of EML4-ALK-positive patients. Accordingly, F-circEA can be used as a diagnostic and therapeutic marker for patients with the EML4-ALK translocation [7]. It has been reported that the expression of has_circ_0000745 is significantly downregulated in both GC tissues and plasma samples obtained from patients with GC. In GC tissues, hsa_circ_0000745 levels are significantly correlated with tumor differentiation. Meanwhile, hsa_circ_0000745 levels in plasma obtained from GC patients are significantly correlated with the TNM stage. As shown in the receiver operating characteristic (ROC) curve generated for plasma has_circ_0000745 levels and CEA levels, the AUC was 0.775 , with a sensitivity and specificity of 0.800 and 0.633 , respectively [93]. In plasma and tissues obtained from GC patients, has_circ_0001017 and has_circ_0061276 were evidently reduced, and these levels were significantly associated with distal metastasis. The AUC of the quadruple combination of has_circ_0001017, has_circ_0061276 in gastric dysplasia and normal controls was 0.966 , with a sensitivity and specificity of $95.5 \%$ and 95.7\%, respectively [94]. Similarly, has_circ_0000520 is significantly deceased in gastric cancer tissues, plasma and gastric cancer cell lines. Has_circ_0000520 level in GC tissues is negatively correlated with TNM stage, and in GC plasma is positively associated with CEA expression. The ROC curve for plasma exhibits that the AUC was 0.8967 with the sensitivity and specificity are $82.35 \%$ and $84.44 \%$, respectively [95]. Moreover, the expression of has_circ_0000190 are suppressed in gastric cancer tissues and plasma samples, which associated with tumor diameter, lymphatic metastasis, distal metastasis, TNM stage and CA19-9 levels. When combine has_circ_0000190 in tissues and plasma, the AUC is up to 0.775, and the sensitivity and specificity are 0.712 and 0.750 [96]. In addition, has_circ_002059 is significantly decreased in gastric tissues, and its levels in plasma from postoperative gastric cancer patients is higher than those from preoperative gastric cancer patients. The expression of has_circ_002059 are evidently correlated with several clinical factors, including distal metastasis, TNM stage, gender and age. The AUC of has_circ_002059 is 0.73 [97]. Circ-LDLRAD3 is upregulated in both pancreatic cancer tissues and plasma obtained from patients with pancreatic cancer, and the AUC value, sensitivity and specificity when combined with CA19-9 was $0.87,0.8033$ and 0.9355 , respectively [70]. Z Kun-Peng et al. discovered that circPVT1 was significantly elevated in the osteosarcoma tissues, serums and chemoresistant cell lines, which was correlated with advanced Enneking stage, chemoresistance and lung metastasis. The ROC curve showed that the AUC is 0.871 , and consequently circPVT1 has the potential to be a diagnosis biomarker in osteosarcoma, comparable to LDH and better than ALP [98]. S Li et al. demonstrated that numerous circRNAs show differential expression in plasma derived from patients before and after cervicectomy. Besides, more than 10,000 circRNAs are detected in plasma from patients with cervical cancer [90]. 
Exosomes are small membrane vesicles secreted by various cell, as well as contain disease-specific protein and nucleic acid. Recent studies have found that circRNAs are abundant in exosomes, and may serve as a new class of exosome-based biomarker. Y Li et al. discovered that more than 1000 circRNAs were identified in the human serum exosomes [99]. Compared to healthy donors, 67 circRNAs were absent and 257 new circRNAs were discovered in CRC patients. Based on serum exosome RNA sequencing (RNA-seq) datasets, the expression of circ-KLDHC10 was upregulated in serum obtained from colorectal cancer (CRC) patients. Circ-PDE8A is abundant in exosomes of circ-PDE8A overexpressing cells, and it can regulate the expression of MACC1 and MET in vitro. The blood exosome circ-PDE8A is existed in the plasma of PDAC patients, and the expression of exosomal circ-PDE8A was associated with duodenal invasion, vascular invasion, $\mathrm{T}$ factor or TNM stage [71]. High quality circRNA candidates are detected in the exosomes of colon cancer cell lines. Moreover, the relative circRNA levels are not associated with their linear mRNA host genes in exosomes [100]. These studies show that serum exo-circRNA (circRNA in exosomes) has potential to be a circulating biomarker for cancer diagnosis. In addition, there is database, exoBase (http://www.exorbase.org/), which provides the expression level and possible original tissues of circRNAs in human blood exosomes, triggering the discovery and research of exo-circRNAs.

\section{Conclusions}

In current study,it is a hot topic about the role of circRNAs in diseases. With the development of next-generation sequencing technologies and other detection technologies, increasingly circRNAs differentially expressed between disease states and normal states can be detected. As a type of disease with high morbidity and mortality, the tumor is a serious threat to human health. Recently, many studies have found that circRNAs play a crucial role in the development of multiple tumors. CircRNAs are in equilibrium under the normal state of the body, and when carcinogenic circRNAs are up-regulated or cancer-suppressing circRNAs are downregulated, tumors will form. The main mechanism of circRNAs in tumors is the miRNA sponge, which acts through the circRNA-miRNA-mRNA regulatory networks. Since Ago2 is one of the major members of RNA-induced silencing complex (RISC), the Ago2 immunoprecipitation assay is widely used to discover the miRNA sponge function of circRNA. CircRNAs regulate the downstream mRNA expression of oncoproteins, tumor suppressor proteins and cell cycle related proteins. However, most circRNAs do not function as microRNA sponges because most of these molecules contain fewer
miRNA binding sites [5]. In addition, circRNAs can bind to proteins and function at the transcriptional, posttranscriptional, and translational levels. Interestingly, endogenous circRNAs have recently been found to encode protein through the $5^{\prime}$ cap-independent translation and play an important role in gliomas, such as circFBXW7 [51] and circSHPRH [52]. Some databases can be used for the prediction of protein-translating circRNAs, such as: circRNADb (http://202.195.183.4:8000/circrnadb/circRNADb.php), circPro (http://bis.zju.edu.cn/CircPro). Further research on the translational function of tumor-associated circRNAs is of great importance for the study of tumorigenesis mechanisms. The formation mechanism of circRNA has been studied more thoroughly, but the mechanism of its degradation remain unclear. Some studies have found that circRNAs are rich in extracellular vesicles [101] and exosomes [99], which may be one of the degradation mechanisms. Hence, further studies on the degradation mechanism of circRNAs are needed. A large number of studies have shown that circRNA is differentially expressed in the plasma of patients and normal subjects, and its tendency is the same as that between tumor tissues and adjacent normal tissues, which has important diagnostic value. However, the research and application of circRNAs in targeted therapy are few. The development direction, including antagonizing circRNA function by siRNA, anti-sense oligonucleotides and CRISPR-Cas9mediated genome editing, promoting circRNA function by a minigene construct [102].

\section{Abbreviations \\ ADAR1: Adenosine deaminase1; AUC: Area under curve; BCa: Bladder cancer; ceRNA: Competing endogenous RNA; circRNA: Circular RNA; CRC: Colorectal cancer; GC: Gastric cancer; HCC: Hepatocellular carcinoma; IRES: Internal ribozyme entry site; LAC: Lung adenocarcinoma; NSCLC: Non-small cell lung cancer; ORF: Open reading frame; OS: Osteosarcoma; OSCC: Oral squamous cell carcinoma; PDAC: Pancreatic ductal adenocarcinoma; RBP: RNA-binding proteins;" ROC: Receiver operating characteristic; TNBC: Triple negative breast cancer}

\section{Funding}

This study was financially supported by the National Natural Science Foundation of China (81770900 and 81622005), the Science and Technology Development Foundation of Shandong Province (2014GHY115025), Qingdao Science and Technology Plan fund (16-6-2-28-NSH).

\section{Authors' contributions}

XLC, WHX and JXW provided direction and guidance throughout the preparation of this manuscript. SL, HRL, WJL, XHY and JPT collected and prepared the related literature. XLC drafted the manuscript. WHX, JXW, ZJG, MYL and MYL reviewed and made significant revisions to the manuscript. All authors have read and approved the final manuscript.

Ethics approval and consent to participate

Not applicable.

Consent for publication

Not applicable.

Competing interests

The authors declare that they have no competing interests. 


\section{Publisher's Note}

Springer Nature remains neutral with regard to jurisdictional claims in published maps and institutional affiliations.

\section{Author details}

'Department of Inspection, The medical faculty of Qingdao University, Qingdao 266003, China. ${ }^{2}$ Center for Regenerative Medicine, Institute for Translational Medicine, Qingdao University, Qingdao 266021, China. ${ }^{3}$ Department of geriatric medical, Affiliated Hospital of Medical College, Qingdao University, Qingdao 266003, China.

\section{Received: 14 June 2018 Accepted: 10 August 2018}

\section{Published online: 15 August 2018}

\section{References}

1. Jeck WR, Sorrentino JA, Wang K, Slevin MK, Burd CE, Liu J, Marzluff WF, Sharpless NE. Circular RNAs are abundant, conserved, and associated with ALU repeats. RNA (New York, NY). 2013;19(2):141-57.

2. Memczak S, Jens M, Elefsinioti A, Torti F, Krueger J, Rybak A, Maier L, Mackowiak SD, Gregersen LH, Munschauer M, et al. Circular RNAs are a large class of animal RNAs with regulatory potency. Nature. 2013;495(7441):333-8.

3. Wang PL, Bao Y, Yee MC, Barrett SP, Hogan GJ, Olsen MN, Dinneny JR, Brown PO, Salzman J. Circular RNA is expressed across the eukaryotic tree of life. PLoS One. 2014;9(6):e90859.

4. Cocquerelle C, Mascrez B, Hetuin D, Bailleul B. Mis-splicing yields circular RNA molecules. FASEB J. 1993:7(1):155-60.

5. Jeck WR, Sharpless NE. Detecting and characterizing circular RNAs. Nat Biotechnol. 2014;32(5):453-61.

6. Qiu M, Xia W, Chen R, Wang S, Xu Y, Ma Z, Xu W, Zhang E, Wang J, Fang T, et al. The circular RNA circPRKCl promotes tumor growth in lung adenocarcinoma. Cancer Res. 2018;78(11):2839-51.

7. Tan S, Gou Q, Pu W, Guo C, Yang Y, Wu K, Liu Y, Liu L, Wei YQ, Peng Y. Circular RNA F-circEA produced from EML4-ALK fusion gene as a novel liquid biopsy biomarker for non-small cell lung cancer. Cell Res. 2018;28(6):693-5.

8. Zeng K, Chen X, Xu M, Liu X, Hu X, Xu T, Sun H, Pan Y, He B, Wang S. CircHIPK3 promotes colorectal cancer growth and metastasis by sponging miR-7. Cell Death Dis. 2018:9(4):417.

9. Hsiao KY, Lin YC, Gupta SK, Chang N, Yen L, Sun HS, Tsai SJ. Noncoding effects of circular RNA CCDC66 promote Colon Cancer growth and metastasis. Cancer Res. 2017;77(9):2339-50

10. Zhang J, Liu H, Hou L, Wang G, Zhang R, Huang Y, Chen X, Zhu J. Circular RNA_LARP4 inhibits cell proliferation and invasion of gastric cancer by sponging miR-424-5p and regulating LATS1 expression. Mol Cancer. 2017; 16(1):151.

11. Chen J, Li Y, Zheng Q, Bao C, He J, Chen B, Lyu D, Zheng B, Xu Y, Long Z, et al. Circular RNA profile identifies circPVT1 as a proliferative factor and prognostic marker in gastric cancer. Cancer Lett. 2017;388:208-19.

12. Chen G, Shi Y, Liu M, Sun J. circHIPK3 regulates cell proliferation and migration by sponging miR-124 and regulating AQP3 expression in hepatocellular carcinoma. Cell Death Dis. 2018;9(2):175.

13. Han D, Li J, Wang H, Su X, Hou J, Gu Y, Qian C, Lin Y, Liu X, Huang M, et al. Circular RNA circMTO1 acts as the sponge of microRNA-9 to suppress hepatocellular carcinoma progression. Hepatology. 2017;66(4):1151-64.

14. Shi L, Yan P, Liang Y, Sun Y, Shen J, Zhou S, Lin H, Liang X, Cai X. Circular RNA expression is suppressed by androgen receptor (AR)-regulated adenosine deaminase that acts on RNA (ADAR1) in human hepatocellular carcinoma. Cell Death Dis. 2017;8(11):e3171.

15. Yu J, Xu QG, Wang ZG, Yang Y, Zhang L, Ma JZ, Sun SH, Yang F, Zhou WP Circular RNA CSMARCA5 inhibits growth and metastasis in hepatocellular carcinoma. J Hepatol. 2018;68(6):1214-27.

16. He R, Liu P, Xie X, Zhou Y, Liao Q, Xiong W, Li X, Li G, Zeng Z, Tang H. circGFRA1 and GFRA1 act as ceRNAs in triple negative breast cancer by regulating miR-34a. J Exp Clin Cancer Res. 2017;36(1):145.

17. Yang Q, Du WW, Wu N, Yang W, Awan FM, Fang L, Ma J, Li X, Zeng Y, Yang

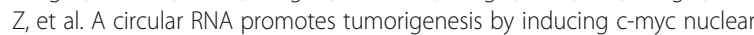
translocation. Cell Death Differ. 2017;24(9):1609-20.

18. Kelly S, Greenman C, Cook PR, Papantonis A. Exon skipping is correlated with exon circularization. J Mol Biol. 2015:427(15):2414-7.

19. Starke S, Jost I, Rossbach O, Schneider T, Schreiner S, Hung LH, Bindereif A. Exon circularization requires canonical splice signals. Cell Rep. 2015;10(1):103-11.
20. Wilusz JE. Circular RNAs: unexpected outputs of many protein-coding genes. RNA Biol. 2017;14(8):1007-17.

21. Aucamp J, Bronkhorst AJ, Pretorius PJ. A historical and evolutionary perspective on circulating nucleic acids and extracellular vesicles: circulating nucleic acids as homeostatic genetic entities. Adv Exp Med Biol. 2016;924:91-5.

22. Monat C, Quiroga C, Laroche-Johnston F, Cousineau B. The LI.LtrB intron from Lactococcus lactis excises as circles in vivo: insights into the group II intron circularization pathway. RNA (New York, NY). 2015;21 (7):1286-93.

23. Li Z, Huang C, Bao C, Chen L, Lin M, Wang X, Zhong G, Yu B, Hu W, Dai L, et al. Exon-intron circular RNAs regulate transcription in the nucleus. Nat Struct Mol Biol. 2015;22(3):256-64.

24. Qu S, Zhong Y, Shang R, Zhang X, Song W, Kjems J, Li H. The emerging landscape of circular RNA in life processes. RNA Biol. 2017;14(8):992-9.

25. Jurica MS, Moore MJ. Pre-mRNA splicing: awash in a sea of proteins. Mol Cell. 2003;12(1):5-14.

26. Ashwal-Fluss R, Meyer M, Pamudurti NR, Ivanov A, Bartok O, Hanan M, Evantal N, Memczak S, Rajewsky N, Kadener S. circRNA biogenesis competes with pre-mRNA splicing. Mol Cell. 2014;56(1):55-66.

27. Zhang Y, Xue W, Li X, Zhang J, Chen S, Zhang JL, Yang L, Chen LL. The biogenesis of nascent circular RNAs. Cell Rep. 2016;15(3):611-24.

28. Kramer MC, Liang D, Tatomer DC, Gold B, March ZM, Cherry S, Wilusz JE. Combinatorial control of Drosophila circular RNA expression by intronic repeats, hnRNPS, and SR proteins. Genes Dev. 2015;29(20):2168-82.

29. Zhang Y, Zhang XO, Chen T, Xiang JF, Yin QF, Xing YH, Zhu S, Yang L, Chen LL. Circular intronic long noncoding RNAs. Mol Cell. 2013;51(6):792-806.

30. Noto JJ, Schmidt CA, Matera AG. Engineering and expressing circular RNAs via tRNA splicing. RNA Biol. 2017;14(8):978-84.

31. Zhang $X O$, Wang HB, Zhang $Y$, Lu X, Chen LL, Yang L. Complementary sequence-mediated exon circularization. Cell. 2014;159(1):134-47.

32. Ivanov A, Memczak S, Wyler E, Torti F, Porath HT, Orejuela MR, Piechotta M, Levanon EY, Landthaler M, Dieterich C, et al. Analysis of intron sequences reveals hallmarks of circular RNA biogenesis in animals. Cell Rep. 2015;10(2):170-7.

33. Liang D, Wilusz JE. Short intronic repeat sequences facilitate circular RNA production. Genes Dev. 2014;28(20):2233-47.

34. Conn SJ, Pillman KA, Toubia J, Conn VM, Salmanidis M, Phillips CA, Roslan S, Schreiber AW, Gregory PA, Goodall GJ. The RNA binding protein quaking regulates formation of circRNAs. Cell. 2015;160(6):1125-34.

35. Errichelli L, Dini Modigliani S, Laneve P, Colantoni A, Legnini I, Capauto D, Rosa A, De Santis R, Scarfo R, Peruzzi G, et al. FUS affects circular RNA expression in murine embryonic stem cell-derived motor neurons. Nat Commun. 2017;8:14741.

36. Rybak-Wolf A, Stottmeister C, Glazar P, Jens M, Pino N, Giusti S, Hanan M, Behm M, Bartok O, Ashwal-Fluss $R$, et al. Circular RNAs in the mammalian brain are highly abundant, conserved, and dynamically expressed. Mol Cell. 2015;58(5):870-85

37. Cesana M, Cacchiarelli D, Legnini I, Santini T, Sthandier O, Chinappi M, Tramontano A, Bozzoni I. A long noncoding RNA controls muscle differentiation by functioning as a competing endogenous RNA. Cell. 2011; 147(2):358-69.

38. Poliseno L, Salmena L, Zhang J, Carver B, Haveman WJ, Pandolfi PP. A coding-independent function of gene and pseudogene mRNAs regulates tumour biology. Nature. 2010;465(7301):1033-8.

39. Karreth FA, Pandolfi PP. ceRNA cross-talk in cancer: when ce-bling rivalries go awry. Cancer Discov. 2013;3(10):1113-21.

40. Hansen TB, Jensen TI, Clausen BH, Bramsen JB, Finsen B, Damgaard CK, Kjems J. Natural RNA circles function as efficient microRNA sponges. Nature. 2013;495(7441):384-8.

41. Hentze MW, Preiss T. Circular RNAs: splicing's enigma variations. EMBO J. 2013:32(7):923-5.

42. Wang $X$, Zhu $X$, Zhang H, Wei S, Chen Y, Chen Y, Wang F, Fan X, Han S, Wu G. Increased circular RNA hsa_circ_0012673 acts as a sponge of miR-22 to promote lung adenocarcinoma proliferation. Biochem Biophys Res Commun. 2018;496(4):1069-75.

43. Huang WJ, Wang YC, Liu SS, Yang JL, Guo SX, Wang LJ, Wang HZ, Fan YF. Silencing circular RNA hsa_circ_0000977 suppresses pancreatic ductal adenocarcinoma progression by stimulating miR-874-3p and inhibiting PLK1 expression. Cancer Lett. 2018;422:70-80.

44. Yang C, Yuan W, Yang X, Li P, Wang J, Han J, Tao J, Li P, Yang H, Lv Q, et al. Circular RNA circ-ITCH inhibits bladder cancer progression by sponging 
miR-17/miR-224 and regulating p21, PTEN expression. Mol Cancer. 2018; 17(1):19.

45. He Q, Zhao L, Liu Y, Liu X, Zheng J, Yu H, Cai H, Ma J, Liu L, Wang P, et al. circ-SHKBP1 regulates the angiogenesis of U87 Glioma-exposed endothelial cells through miR-544a/FOXP1 and miR-379/FOXP2 pathways. Mol Ther Nucleic Acids. 2018:10:331-48.

46. Chen L, Zhang S, Wu J, Cui J, Zhong L, Zeng L, Ge S. circRNA_100290 plays a role in oral cancer by functioning as a sponge of the miR-29 family. Oncogene. 2017;36(32):4551-61.

47. Zhang H, Wang G, Ding C, Liu P, Wang R, Ding W, Tong D, Wu D, Li C, Wei $Q$, et al. Increased circular RNA UBAP2 acts as a sponge of miR-143 to promote osteosarcoma progression. Oncotarget. 2017;8(37):61687-97.

48. Legnini I, Di Timoteo G, Rossi F, Morlando M, Briganti F, Sthandier O, Fatica A, Santini T, Andronache A, Wade M, et al. Circ-ZNF609 is a Circular RNA that Can Be Translated and Functions in Myogenesis. Mol Cell. 2017;66(1):22-37.e29.

49. Pamudurti NR, Bartok O, Jens M, Ashwal-Fluss R, Stottmeister C, Ruhe L, Hanan M, Wyler E, Perez-Hernandez D, Ramberger E, et al. Translation of CircRNAs. Mol cell. 2017;66(1):9-21.e27.

50. Yang Y, Fan X, Mao M, Song X, Wu P, Zhang Y, Jin Y, Yang Y, Chen LL, Wang $Y$, et al. Extensive translation of circular RNAs driven by N(6)methyladenosine. Cell Res. 2017;27(5):626-41.

51. Yang $Y$, Gao X, Zhang M, Yan S, Sun C, Xiao F, Huang N, Yang X, Zhao K, Zhou $H$, et al. Novel Role of FBXW7 Circular RNA in Repressing Glioma Tumorigenesis. J Natl Cancer Inst. 2018:110(3):304-15.

52. Zhang M, Huang N, Yang X, Luo J, Yan S, Xiao F, Chen W, Gao X, Zhao K, Zhou $\mathrm{H}$, et al. A novel protein encoded by the circular form of the SHPRH gene suppresses glioma tumorigenesis. Oncogene. 2018;37(13):1805-14

53. Du WW, Yang W, Liu E, Yang Z, Dhaliwal P, Yang BB. Foxo3 circular RNA retards cell cycle progression via forming ternary complexes with p21 and CDK2. Nucleic Acids Res. 2016;44(6):2846-58.

54. Guarnerio J, Bezzi M, Jeong JC, Paffenholz SV, Berry K, Naldini MM, LoCoco F, Tay Y, Beck AH, Pandolfi PP. Oncogenic role of fusion-circRNAs derived from Cancer-associated chromosomal translocations. Cell. 2016; 165(2):289-302.

55. Smith RA, Manassaram-Baptiste D, Brooks D, Doroshenk M, Fedewa S, Saslow D, Brawley OW, Wender R. Cancer screening in the United States, 2015: a review of current American cancer society guidelines and current issues in cancer screening. CA Cancer J Clin. 2015;65(1):30-54.

56. Siegel RL, Miller KD, Jemal A. Cancer statistics, 2018. CA Cancer J Clin. 2018; 68(1):7-30.

57. Zhu X, Wang $X$, Wei S, Chen Y, Chen Y, Fan X, Han S, Wu G. hsa_circ 0013958: a circular RNA and potential novel biomarker for lung adenocarcinoma. FEBS J. 2017;284(14):2170-82.

58. Zong L, Sun $Q$, Zhang H, Chen Z, Deng Y, Li D, Zhang L. Increased expression of circRNA_102231 in lung cancer and its clinical significance. Biomed Pharmacother. 2018;102:639-44.

59. Jiang MM, Mai ZT, Wan SZ, Chi YM, Zhang X, Sun BH, Di QG. Microarray profiles reveal that circular RNA hsa_circ_0007385 functions as an oncogene in non-small cell lung cancer tumorigenesis. J Cancer Res Clin Oncol. 2018; 144(4):667-74

60. Dai X, Zhang N, Cheng Y, Yang T, Chen Y, Liu Z, Wang Z, Yang C, Jiang Y. RNA-binding protein Trinucleotide repeat-containing 6 A regulates the formation of circular RNA 0006916, with important functions in lung Cancer cells. Carcinogenesis. 2018;39(8):981-92.

61. Liu W, Ma W, Yuan Y, Zhang Y, Sun S. Circular RNA hsa_circRNA_103809 promotes lung cancer progression via facilitating ZNF121-dependent MYC expression by sequestering miR-4302. Biochem Biophys Res Commun. 2018:500(4):846-51.

62. Zhao F, Han Y, Liu Z, Zhao Z, Li Z, Jia K. circFADS2 regulates lung cancer cells proliferation and invasion via acting as a sponge of miR-498. Biosci Rep. 2018. https://doi.org/10.1042/BSR20180570. [Epub ahead of print]

63. Hang D, Zhou J, Qin N, Zhou W, Ma H, Jin G, Hu Z, Dai J, Shen H. A novel plasma circular RNA circFARSA is a potential biomarker for non-small cell lung cancer. Cancer Med. 2018;7(6):2783-91.

64. Weng W, Wei Q, Toden S, Yoshida K, Nagasaka T, Fujiwara T, Cai S, Qin H, Ma Y, Goel A. Circular RNA ciRS-7-a promising prognostic biomarker and a potential therapeutic target in colorectal Cancer. Clin Cancer Res. 2017; 23(14):3918-28.

65. Zhu M, Xu Y, Chen Y, Yan F. Circular BANP, an upregulated circular RNA that modulates cell proliferation in colorectal cancer. Biomed Pharmacother. 2017:88:138-44
66. Wang F, Wang J, Cao X, Xu L, Chen L. Hsa_circ_0014717 is downregulated in colorectal cancer and inhibits tumor growth by promoting p16 expression. Biomed Pharmacother. 2018;98:775-82.

67. Torre LA, Bray F, Siegel RL, Ferlay J, Lortet-Tieulent J, Jemal A. Global cancer statistics, 2012. CA Cancer J Clin. 2015;65(2):87-108.

68. Li P, Chen H, Chen S, Mo X, Li T, Xiao B, Yu R, Guo J. Circular RNA 0000096 affects cell growth and migration in gastric cancer. Br J Cancer. 2017;116(5):626-33.

69. Chen W, Zheng R, Baade PD, Zhang S, Zeng H, Bray F, Jemal A, Yu XQ, He J. Cancer statistics in China, 2015. CA Cancer J Clin. 2016;66(2):115-32.

70. Yang F, Liu DY, Guo JT, Ge N, Zhu P, Liu X, Wang S, Wang GX, Sun SY. Circular RNA circ-LDLRAD3 as a biomarker in diagnosis of pancreatic cancer. World J Gastroenterol. 2017;23(47):8345-54.

71. Li Z, Yanfang W, Li J, Jiang P, Peng T, Chen K, Zhao X, Zhang Y, Zhen P, Zhu $J$, et al. Tumor-released exosomal circular RNA PDE8A promotes invasive growth via the miR-338/MACC1/MET pathway in pancreatic cancer. Cancer Lett. 2018;432:237-50.

72. Zhu Q, Lu G, Luo Z, Gui F, Wu J, Zhang D, Ni Y. CircRNA circ_0067934 promotes tumor growth and metastasis in hepatocellular carcinoma through regulation of miR-1324/FZD5/Wnt/beta-catenin axis. Biochem Biophys Res Commun. 2018;497(2):626-32.

73. Huang $X Y$, Huang $Z L$, Xu YH, Zheng $Q$, Chen Z, Song W, Zhou J, Tang ZY, Huang XY. Comprehensive circular RNA profiling reveals the regulatory role of the circRNA-100338/miR-141-3p pathway in hepatitis B-related hepatocellular carcinoma. Sci Rep. 2017;7(1):5428.

74. Zhong L, Wang Y, Cheng Y, Wang W, Lu B, Zhu L, Ma Y. Circular RNA circC3P1 suppresses hepatocellular carcinoma growth and metastasis through miR-4641/PCK1 pathway. Biochem Biophys Res Commun. 2018; 499(4):1044-9.

75. Wang H, Xiao Y, Wu L, Ma D. Comprehensive circular RNA profiling reveals the regulatory role of the circRNA-000911/miR-449a pathway in breast carcinogenesis. Int J Oncol. 2018;52(3):743-54.

76. Liang HF, Zhang XZ, Liu BG, Jia GT, Li WL. Circular RNA circ-ABCB10 promotes breast cancer proliferation and progression through sponging miR-1271. Am J Cancer Res. 2017;7(7):1566-76.

77. Zhou J, Zhang WW, Peng F, Sun JY, He ZY, Wu SG. Downregulation of hsa_ circ_0011946 suppresses the migration and invasion of the breast cancer cell line MCF-7 by targeting RFC3. Cancer Manag Res. 2018;10:535-44.

78. Antoni S, Ferlay J, Soerjomataram I, Znaor A, Jemal A, Bray F. Bladder Cancer incidence and mortality: a global overview and recent trends. Eur Urol. 2017;71(1):96-108.

79. Zhong Z, Huang M, Lv M, He Y, Duan C, Zhang L, Chen J. Circular RNA MYLK as a competing endogenous RNA promotes bladder cancer progression through modulating VEGFANEGFR2 signaling pathway. Cancer Lett. 2017:403:305-17.

80. Li Y, Zheng F, Xiao X, Xie F, Tao D, Huang C, Liu D, Wang M, Wang L, Zeng $F$, et al. CircHIPK3 sponges miR-558 to suppress heparanase expression in bladder cancer cells. EMBO Rep. 2017:18(9):1646-59.

81. Li P, Yang X, Yuan W, Yang C, Zhang X, Han J, Wang J, Deng X, Yang H, Li $P$, et al. CircRNA-Cdr1as exerts anti-oncogenic functions in bladder Cancer by sponging MicroRNA-135a. Cell Physiol Biochem. 2018;46(4):1606-16.

82. Zheng J, Liu X, Xue Y, Gong W, Ma J, Xi Z, Que Z, Liu Y. TTBK2 circular RNA promotes glioma malignancy by regulating miR-217/HNF1 beta/Derlin-1 pathway. J Hematol Oncol. 2017;10(1):52.

83. Wang L, Wei Y, Yan Y, Wang H, Yang J, Zheng Z, Zha J, Bo P, Tang Y, Guo X, et al. CircDOCK1 suppresses cell apoptosis via inhibition of miR196a5p by targeting BIRC3 in OSCC. Oncol Rep. 2018;39(3):951-66.

84. Liu X, Zhong Y, Li J, Shan A. Circular RNA circ-NT5C2 acts as an oncogene in osteosarcoma proliferation and metastasis through targeting miR-448. Oncotarget. 2017;8(70):114829-38.

85. Deng N, Li L, Gao J, Zhou J, Wang Y, Wang C, Liu Y. Hsa_circ_0009910 promotes carcinogenesis by promoting the expression of miR-449a target IL6R in osteosarcoma. Biochem Biophys Res Commun. 2018;495(1):189-96.

86. Huang L, Chen M, Pan J, Yu W. Circular RNA circNASP modulates the malignant behaviors in osteosarcoma via miR-1253/FOXF1 pathway. Biochem Biophys Res Commun. 2018;500(2):511-7.

87. Song YZ, Li JF. Circular RNA hsa_circ_0001564 regulates osteosarcoma proliferation and apoptosis by acting miRNA sponge. Biochem Biophys Res Commun. 2018:495(3):2369-75.

88. Salzman J, Gawad C, Wang PL, Lacayo N, Brown PO. Circular RNAs are the predominant transcript isoform from hundreds of human genes in diverse cell types. PLoS One. 2012;7(2):e30733. 
89. Suzuki H, Tsukahara T. A view of pre-mRNA splicing from RNase R resistant RNAs. Int J Mol Sci. 2014;15(6):9331-42.

90. Li S, Teng S, Xu J, Su G, Zhang Y, Zhao J, Zhang S, Wang H, Qin W, Lu ZJ, et al. Microarray is an efficient tool for circRNA profiling. Brief Bioinform. 2018. https://doi.org/10.1093/bib/bby006. [Epub ahead of print]

91. Bahn JH, Zhang Q, Li F, Chan TM, Lin X, Kim Y, Wong DT, Xiao X. The landscape of microRNA, Piwi-interacting RNA, and circular RNA in human saliva. Clin Chem. 2015;61(1):221-30.

92. Memczak S, Papavasileiou P, Peters O, Rajewsky N. Identification and characterization of circular RNAs as a new class of putative biomarkers in human blood. PLoS One. 2015;10(10):e0141214.

93. Huang M, He YR, Liang LC, Huang Q, Zhu ZQ. Circular RNA hsa_circ_ 0000745 may serve as a diagnostic marker for gastric cancer. World J Gastroenterol. 2017;23(34):6330-8.

94. Li T, Shao Y, Fu L, Xie Y, Zhu L, Sun W, Yu R, Xiao B, Guo J. Plasma circular RNA profiling of patients with gastric cancer and their droplet digital RTPCR detection. J Mol Med. 2018:96(1):85-96.

95. Sun H, Tang W, Rong D, Jin H, Fu K, Zhang W, Liu Z, Cao H, Cao X. Hsa_ circ_0000520, a potential new circular RNA biomarker, is involved in gastric carcinoma. Cancer Biomark. 2018;21 (2):299-306.

96. Chen S, Li T, Zhao Q, Xiao B, Guo J. Using circular RNA hsa_circ_0000190 as a new biomarker in the diagnosis of gastric cancer. Clin Chim Acta. 2017; 466:167-71

97. Li P, Chen S, Chen H, Mo X, Li T, Shao Y, Xiao B, Guo J. Using circular RNA as a novel type of biomarker in the screening of gastric cancer. Clin Chim Acta. 2015:444:132-6.

98. Kun-Peng Z, Xiao-Long M, Chun-Lin Z. Overexpressed circPVT1, a potential new circular RNA biomarker, contributes to doxorubicin and cisplatin resistance of osteosarcoma cells by regulating ABCB1. Int J Biol Sci. 2018; 14(3):321-30.

99. Li Y, Zheng Q, Bao C, Li S, Guo W, Zhao J, Chen D, Gu J, He X, Huang S. Circular RNA is enriched and stable in exosomes: a promising biomarker for cancer diagnosis. Cell Res. 2015;25(8):981-4.

100. Dou Y, Cha DJ, Franklin JL, Higginbotham JN, Jeppesen DK, Weaver AM, Prasad N, Levy S, Coffey RJ, Patton JG, et al. Circular RNAs are downregulated in KRAS mutant colon cancer cells and can be transferred to exosomes. Sci Rep. 2016;6:37982.

101. Lasda E, Parker R. Circular RNAs co-precipitate with extracellular vesicles: a possible mechanism for circRNA clearance. PLoS One. 2016;11(2):e0148407.

102. Zhang M, Xin Y. Circular RNAs: a new frontier for cancer diagnosis and therapy. J Hematol Oncol. 2018;11(1):21.

Ready to submit your research? Choose BMC and benefit from:

- fast, convenient online submission

- thorough peer review by experienced researchers in your field

- rapid publication on acceptance

- support for research data, including large and complex data types

- gold Open Access which fosters wider collaboration and increased citations

- maximum visibility for your research: over $100 \mathrm{M}$ website views per year

At $\mathrm{BMC}$, research is always in progress.

Learn more biomedcentral.com/submissions 